\title{
Diagnosis penguasaan kemahiran dan kesilapan pelajar tingkatan satu bagi tajuk Pembinaan Geometri
}

\author{
Shariza Fazliana Mat Yusof ${ }^{1}$, Tee Sok Ting $^{2} \&$ Hafsah Taha ${ }^{3}$ \\ ${ }^{1}$ Kolej Matrikulasi Kejuruteraan Pahang ${ }^{2}$ SJKC Yit Khwan ${ }^{3}$ Universiti Pendidikan Sultan Idris \\ ${ }^{1}$ shariza_yusof@yahoo.com ${ }^{2}$ sokting_tee@yahoo.com ${ }^{3}$ hafsah@fsmt.upsi.edu.my
}

DOI: https://doi.org/10.37134/ejoss.vol5.1.2.2019

\begin{abstract}
Abstrak
Tujuan kajian ini dijalankan adalah untuk mengenal pasti kefahaman dan kesilapan pelajar dalam membina sudut $30^{\circ}, 60^{\circ}, 45^{\circ}$ dan $90^{\circ}$ serta pembahagi dua sama sudut dalam kalangan pelajar tingkatan satu. Pelajar juga diharapkan dapat menerangkan langkah-langkah pembinaan yang dibuat. Kajian kualitatif ini menggunakan rekabentuk kajian kes dan kaedah persampelan bertujuan. Tiga orang pelajar tingkatan satu terpilih sebagai responden kajian. Instrumen yang digunakan untuk mengumpul data adalah protokol pemerhatian pemikiran verbal (think-aloud interview protocol). Kajian mendapati pelajar menghadapi masalah dalam pembinaan sudut dan tidak dapat melabelkan sudut dengan betul. Pelajar juga kurang mahir menggunakan alat tepi lurus.
\end{abstract}

Katakunci pembinaan sudut, pembahagi dua sama sudut, kemahiran membina sudut

\section{PENDAHULUAN}

Pengetahuan dan kemahiran dalam bidang bentuk dan ruang serta perkaitannya dengan topik-topik lain adalah berguna dalam situasi harian. Dengan meningkatkan kefahaman pelajar tentang aspek ini, mereka boleh menyelesaikan masalah berkaitan geometri dengan berkesan. Di samping itu murid juga dapat mengembangkan pemikiran secara visual dan menghayati nilai estetik yang terdapat pada bentuk dan ruang (Sukatan Pelajaran KBSM, 2000). Tajuk Garis dan Sudut sukatan pembelajaran matematik tingkatan satu dan tiga merupakan antara pengetahuan asas dalam matematik yang sering diaplikasikan kepada beberapa mata pelajaran lain. Dalam kajian Meor Ibrahim Bin Kamarudin dan Siti Hajar Binti Ramzan yang bertajuk 'Tahap Penguasaan Topik Garis dan Sudut Dalam Kalangan Pelajar Pendidikan Matematik UTM' mendapati bahawa pelajar di peringkat universiti juga menghadapi masalah dalam semua aspek kemahiran dan konsep dalam topik Garis dan Sudut. Manakala dalam kajian Azlina Mohd Kosnin dan Lok Yian Lin mendapati bahawa penggunaan perisian Geometer's Sketchpad adalah berkesan dalam membantu pelajar yang berpencapaian rendah dalam tajuk pembinaan geometri. Ini adalah kerana kajian tersebut telah mengenalpasti bahawa pelajar menghadapi masalah memahami dan menguasai konsep geometri dalam tajuk pembinaan geometri. Justeru itu, kajian ini dijalankan untuk mengkaji kefahaman dan melihat kemahiran membina sudut dalam kalangan pelajar tingkatan 1 di sekolah menengah luar bandar.

\section{OBJEKTIF KAJIAN}

Matlamat kajian ini adalah untuk mengenal pasti tahap kefahaman dan kemahiran pelajar serta kesilapan yang dilakukan mereka semasa melakukan pembinaan sudut sudut $30^{\circ}, 60^{\circ}, 45^{\circ}$ dan $90^{\circ}$ serta pembahagi dua sama sudut. Seterusnya, penyelidik berhasrat:

(i) Mengkaji kebolehan dan kemahiran pelajar Tingkatan 1 menggunakan alat tepi lurus dan jangka lukis ;

(ii) Menganalisis punca masalah yang dihadapi oleh pelajar Tingkatan 1 semasa melaksanakan pembinaan geometri. 


\section{Persoalan kajian}

Persoalan kajian adalah seperti berikut :

(i) Adakah pelajar telah memahami konsep dan kemahiran yang perlu dikuasai dalam subtopik garis dan sudut?

(ii) Apakah masalah yang dihadapi oleh pelajar semasa melaksanakan pembinaan geometri ?

\section{METODOLOGI}

\section{Reka bentuk Kajian}

Menurut Ahmad Mahdzan Ayob (1995), kaedah penyelidikan merupakan segala langkah yang diambil untuk mencapai objektif kajian. Pendekatan kualitatif berasaskan kualiti dan bersifat deskriptif yang lebih kepada penghuraian makna perkara-perkara yang dikaji. Pendekatan kajian yang dipilih adalah pendekatan kualitatif dengan memilih rekabentuk kajian kes. Kajian kes boleh membantu pemahaman sesuatu isu secara terperinci, di samping menambah pengetahuan sedia ada serta melihat hubungan yang wujud berhubung fenomena atau isu tersebut. Kajian kes ialah rekabentuk penyelidikan yang paling sesuai digunakan jika fokus penyelidikan adalah tentang proses kerana dapat memberikan gambaran atau pola untuk memahami proses tersebut (Merriam, 2001).

Sebelum kajian sebenar dijalankan, kajian rintis dijalankan terlebih dahulu bertujuan menguji serta menyemak instrumen senarai semak pemerhatian (observation checklist) dan protokol pemikiran verbal (think aloud protocol). Kajian rintis merupakan jenis penyelidikan berskala kecil yang dilakukan sebelum menjalankan kajian sebenar. Tujuan kajian rintis ini adalah untuk mengetahui sejauh mana kesesuaian penggunaan keseluruhan instrumen terhadap respondan, selain mengetahui pemahaman respondan terhadap protokol pemikiran verbal yang digunakan.

Kajian rintis telah dijalankan di sebuah sekolah menengah luar bandar yang mempunyai ciri dan latar belakang yang hampir sama dengan sekolah kajian yang sebenar. Bilangan repondan yang dipilih untuk kajian rintis adalah dua orang pelajar tingkatan satu. Hasil dapatan yang diperoleh daripada kajian rintis mendapati bahawa respondan tersebut tiada masalah dari segi arahan membina sudut dan boleh menjawab soalan yang ditanya semasa sesi protokol pemikiran verbal. Instrumen tersebut telah disemak dan ditambahbaik oleh dua orang pakar matematik bagi tujuan kesahan instrumen. Bagi menentukan kesahan kandungan dalam instrumen kajian yang digunakan, maka semua item telah disemak dan dinilai oleh dua orang pakar yang sesuai dalam bidang Pendidikan Matematik. Pakar pertama ialah Dr Faizal Nizam Lee Abdullah dan pakar kedua ialah Puan Suhana Binti Mohamed Saed, pensyarah Matematik Kolej Matrikulasi.

\section{Sampel Kajian}

Sampel yang dipilih adalah daripada pelajar tingkatan satu yang mengikuti mata pelajaran matematik di sebuah sekolah menengah harian luar bandar. Mereka kemudian dipilih melalui kaedah persampelan tujuan (purposive sampling) dan sampel terpilih terdiri daripada tiga orang pelajar tingkatan satu daripada pelbagai pencapaian.

\section{Instrumen Kajian}

Instrumen yang digunakan bagi menjalankan kajian ini ialah senarai semak pemerhatian dan protokol temubual pemikiran verbal. Kedua - dua instrumen ini digunakan untuk mengukur sejauh mana kefahaman dan kemahiran pelajar bagi subtopik pembinaan geometri. 


\section{Senarai Semak Pemerhatian}

Rajah 1 Senarai Semak Pemerhatian

\begin{tabular}{|c|c|c|c|c|c|c|}
\hline \multicolumn{7}{|c|}{ CLASSROOM OBSERVATION CHECKLIST } \\
\hline \multicolumn{2}{|c|}{ NAMA PELAJAR: } & & & \multicolumn{2}{|c|}{ TARIKH : } & \\
\hline \multicolumn{2}{|r|}{ KELAS : } & & & \multicolumn{2}{|c|}{ WAKTU : } & \\
\hline \multicolumn{2}{|r|}{ TOPIK : } & \multicolumn{5}{|l|}{ BAB 8 : SUDUT DAN GARIS } \\
\hline \multicolumn{2}{|c|}{ TINGKATAN : } & \multicolumn{5}{|l|}{1} \\
\hline \multicolumn{2}{|c|}{$\begin{array}{r}\text { OBJEKTIF PEMBELAJARAN } \\
: \text { : }\end{array}$} & \multicolumn{5}{|c|}{$\begin{array}{l}\text { Melaksanakan pembinaanmenggunakan alat tepi lurus (pembaris dan } \\
\text { jangka lukis) }\end{array}$} \\
\hline \multicolumn{2}{|c|}{ HASIL PEMBELAJARAN : } & \multicolumn{5}{|c|}{ Membina sudut $30^{\circ}, 60^{\circ}, 45^{\circ}, 90^{\circ}$ dan pembahagi dua sama sudut. } \\
\hline PERKARA & \multicolumn{2}{|r|}{ PROSEDUR / KEMAHIRAN } & \multicolumn{3}{|c|}{ DARJAH PERSETUJUAN } & $\begin{array}{l}\text { KOMEN / } \\
\text { CATATAN }\end{array}$ \\
\hline \multirow[t]{2}{*}{ Langkah 1: } & \multicolumn{2}{|c|}{$\begin{array}{l}\text { Melukis satu garis lurus dan labelkan } \\
\text { sebagai } R S \text {. }\end{array}$} & \multirow[t]{2}{*}{ Ya } & \multirow[t]{2}{*}{\begin{tabular}{c|} 
Tidak \\
Lengkap
\end{tabular}} & \multirow[t]{2}{*}{ Tiada } & \\
\hline & & $S$ & & & & \\
\hline Langkah 2: & $\begin{array}{l}\text { Membuk } \\
\text { separuh } \\
\text { (Pastikan } \\
\text { berubah) }\end{array}$ & $\begin{array}{l}\text { a jangka lukis dengan kadar } \\
\text { dari panjang garis } R S \text {. } \\
\text { bukaan jangka lukis tidak }\end{array}$ & $\mathrm{Ya}$ & \begin{tabular}{c|} 
Tidak \\
Lengkap
\end{tabular} & Tiada & \\
\hline
\end{tabular}

Pemerhatian yang dijalankan dalam kajian ini menggunakan borang yang telah disediakan di awal proses kajian. Pemerhatian ini dijalankan semasa aktiviti dalam kelas selepas sesi pengajaran dan pembelajaran. Kemahiran yang diperhatikan semasa pelajar membina sudut $30^{\circ}, 60^{\circ}, 45^{\circ}$ dan $90^{\circ}$ serta pembahagi dua sama sudut dicatat dalam borang pemerhatian. Borang senarai semak pemerhatian adalah seperti rajah 1 manakala protokol pemikiran verbal adalah seperti rajah 2 berikut.

Rajah 2 Protokol Pemikiran Verbal (think aloud)

\begin{tabular}{|c|c|c|c|c|}
\hline \multicolumn{5}{|c|}{ Think Aloud Protocols } \\
\hline \multicolumn{2}{|c|}{ NAMA PELAIAR : } & & TARIKH : & \\
\hline & KELAS : & & WAKTU & \\
\hline & TOPIK : & \multicolumn{3}{|l|}{ BAB $8:$ SUDUT DAN GARIS } \\
\hline \multicolumn{2}{|c|}{ TINGKATAN : } & \multicolumn{3}{|l|}{1} \\
\hline \multicolumn{2}{|c|}{ OBJEKTIF PEMBELAIARAN : } & \multicolumn{3}{|c|}{$\begin{array}{l}\text { Melaksanakan pembinaan menggunakan alat tepi lurus (pembaris dan } \\
\text { jangka lukis) }\end{array}$} \\
\hline \multicolumn{2}{|c|}{ HASIL PEMBELAJARAN : } & \multicolumn{3}{|c|}{ Membina sudut $30^{\circ}, 60^{\circ}, 45^{\circ}, 90^{\circ}$ dan pembahagi dua sama sudut. } \\
\hline PERKARA & \multicolumn{3}{|c|}{ SOALAN/ARAHAN } & CATATAN \\
\hline \multicolumn{5}{|c|}{ E) Membina sudut $60^{\circ}$ di $\angle R S T$. } \\
\hline Sebelum: & \multicolumn{3}{|c|}{$\begin{array}{l}\text { Bagi tajuk Pembinaan Geometri hari ini, kita perlu membina } \\
\text { sudut } 60^{\circ} \text { di } \angle R S T \text {. Saya nak kamu think aloud semasa } \\
\text { menyempurnakan soalan ini. Beritahu apa yang bermain dalam } \\
\text { minda kamu. } \\
\text { 1. Apakah cara yang boleh kita gunakan untuk melukis } \\
\text { sudut } 60^{\circ} \text { di } \angle R S T \text { tanpa menggunakan protraktor? } \\
\text { 2. Apakah peralatan yang diperlukan? } \\
\text { 3. Bagaimana untuk memulakannya? }\end{array}$} & \\
\hline
\end{tabular}




\section{ANALISIS DAPATAN DAN PERBINCANGAN}

Setelah mengumpul data yang diperlukan, data dianalisa dan hasil analisis merupakan masalah yang dihadapi pelajar tingkatan 1 dalam pembinaan geometri. Untuk data penyusunan masalah tajuk pembinaan geometri tingkatan 1 , data tersebut dikategorikan mengikut sub tajuk kecil, iaitu pembinaan sudut $\left(60^{\circ}\right.$ dan $\left.90^{\circ}\right)$ dan pembinaan pembahagi dua sama sudut $\left(30^{\circ}\right.$ dan $\left.45^{\circ}\right)$. Pelajar dianggap menghadapi masalah jika tidak dapat membina sudut tersebut dengan betul.

Jadual 1 Bahagian A (Membina sudut $60^{\circ}$ di $\angle R S T$ )

\begin{tabular}{|c|c|c|c|c|}
\hline \multirow{2}{*}{ Langkah } & \multirow{2}{*}{ Penerangan } & \multicolumn{3}{|c|}{ Pelajar } \\
\hline & & $\mathrm{J}$ & $\mathrm{N}$ & $\mathrm{R}$ \\
\hline 1 & $\begin{array}{l}\text { Melukis } \\
\text { satu garis } \\
\text { lurus dan } \\
\text { labelkan } \\
\text { sebagai RS }\end{array}$ & $\begin{array}{l}\text { Melukis } \\
\text { garis dan } \\
\text { labelkan } \\
\text { sebagai } \\
\text { RS }\end{array}$ & $\begin{array}{l}\text { Melukis } \\
\text { garis dan } \\
\text { labelkan } \\
\text { sebagai ST }\end{array}$ & $\begin{array}{l}\text { Melukis } \\
\text { garis dan } \\
\text { labelkan } \\
\text { sebagai } \\
\text { RS }\end{array}$ \\
\hline 2 & $\begin{array}{l}\text { Membuka } \\
\text { jangka } \\
\text { lukis } \\
\text { dengan } \\
\text { kadar } \\
\text { separuh } \\
\text { dari } \\
\text { panjang } \\
\text { garis RS }\end{array}$ & $\begin{array}{l}\text { Membuka } \\
\text { jangka } \\
\text { lukis } \\
\text { dengan } \\
\text { kadar } \\
\text { melebihi } \\
\text { separuh } \\
\text { dari } \\
\text { panjang } \\
\text { garis RS }\end{array}$ & $\begin{array}{l}\text { Membuka } \\
\text { jangka } \\
\text { lukis } \\
\text { dengan } \\
\text { kadar } \\
\text { melebihi } \\
\text { separuh } \\
\text { dari } \\
\text { panjang } \\
\text { garis ST }\end{array}$ & $\begin{array}{l}\text { Membuk } \\
\text { a jangka } \\
\text { lukis } \\
\text { dengan } \\
\text { kadar } \\
\text { kurang } \\
\text { daripada } \\
\text { separuh } \\
\text { dari } \\
\text { panjang } \\
\text { garis RS }\end{array}$ \\
\hline 3 & $\begin{array}{l}\text { Letakkan } \\
\text { jangka } \\
\text { lukis pada } \\
\text { titik S dan } \\
\text { lukiskan } \\
\text { satu } \\
\text { lengkok }\end{array}$ & $\begin{array}{l}\text { Letakkan } \\
\text { jangka } \\
\text { lukis pada } \\
\text { titik R dan } \\
\text { lukiskan } \\
\text { satu } \\
\text { lengkok }\end{array}$ & $\begin{array}{l}\text { Letakkan } \\
\text { jangka } \\
\text { lukis pada } \\
\text { titik S dan } \\
\text { lukiskan } \\
\text { satu } \\
\text { lengkok }\end{array}$ & $\begin{array}{l}\text { Letakkan } \\
\text { jangka } \\
\text { lukis } \\
\text { pada titik } \\
\text { S dan } \\
\text { lukiskan } \\
\text { satu } \\
\text { lengkok }\end{array}$ \\
\hline 4 & $\begin{array}{l}\text { Letakkan } \\
\text { jangka } \\
\text { lukis di } \\
\text { titik } \\
\text { persilangan } \\
\text { dan } \\
\text { lukiskan } \\
\text { satu } \\
\text { lengkok }\end{array}$ & $\begin{array}{l}\text { Letakkan } \\
\text { jangka } \\
\text { lukis di } \\
\text { titik } \\
\text { persilanga } \\
\text { n dan } \\
\text { lukiskan } \\
\text { satu } \\
\text { lengkok } \\
\end{array}$ & $\begin{array}{l}\text { Letakkan } \\
\text { jangka } \\
\text { lukis di } \\
\text { titik } \\
\text { persilangan } \\
\text { dan } \\
\text { lukiskan } \\
\text { satu } \\
\text { lengkok }\end{array}$ & $\begin{array}{l}\text { Letakkan } \\
\text { jangka } \\
\text { lukis di } \\
\text { titik } \\
\text { persilang } \\
\text { an dan } \\
\text { lukiskan } \\
\text { satu } \\
\text { lengkok }\end{array}$ \\
\hline 5 & $\begin{array}{l}\text { Dengan } \\
\text { menggunak } \\
\text { an } \\
\text { pembaris, } \\
\text { sambungka } \\
\text { n titik S ke } \\
\text { titik } \\
\text { persilangan } \\
\text {. Labelkan } \\
\text { sudut } \\
\angle R S T\end{array}$ & $\begin{array}{l}\text { Dengan } \\
\text { mengguna } \\
\text { kan } \\
\text { pembaris, } \\
\text { sambungk } \\
\text { an titik R } \\
\text { ke titik } \\
\text { persilanga } \\
\text { n. } \\
\text { Labelkan } \\
\text { sudut } \\
\angle S R T\end{array}$ & $\begin{array}{l}\text { Dengan } \\
\text { menggunak } \\
\text { an } \\
\text { pembaris, } \\
\text { sambungka } \\
\text { n titik S ke } \\
\text { titik } \\
\text { persilangan } \\
\text {. Labelkan } \\
\text { sudut } \\
\angle T S R\end{array}$ & $\begin{array}{l}\text { Dengan } \\
\text { menggun } \\
\text { akan } \\
\text { pembaris, } \\
\text { sambung } \\
\text { kan titik } \\
\text { S ke titik } \\
\text { persilang } \\
\text { an. } \\
\text { Labelkan } \\
\text { sudut } \\
\angle R S T\end{array}$ \\
\hline
\end{tabular}


Semasa melukis sudut $60^{\circ}$, pemerhatian dilakukan dan pelajar digalakkan untuk menyuarakan apa yang bermain dalam minda mereka. Semasa membina sudut $60^{\circ}$, pelajar $\mathrm{J}$ amat yakin dengan kebolehan diri dengan melakukan pembinaan dengan pantas di samping memberitahu setiap langkah yang dilakukannya. Akan tetapi, dia berasa ragu-ragu dengan perlabelannya setelah selesai pembinaan. Akhirnya, dia membuat keputusan bahawa labelnya adalah betul.

Pelajar N pula lebih berhati-hati semasa melakukan pembinaan sudut $60^{\circ}$. Kelihatan dia melukis dan memadam lukisannya berulang kali untuk mendapatkan lukisan yang betul. Bagi pelajar $\mathrm{R}$ pula, walaupun dia membuka jangka lukis dengan kadar kurang daripada separuh dari panjang garis RS di langkah 2, tetapi dia masih dapat menghasilkan pembinaan sudut $60^{\circ}$ dengan betul dan labelkan sudut itu dengan betul.

Jadual 2 Bahagian B (Membina sudut $30^{\circ}$ di $\angle R S U$ dengan melukis pembahagi dua sama sudut)

\begin{tabular}{|c|c|c|c|c|}
\hline \multirow{2}{*}{ Langkah } & \multirow{2}{*}{ Penerangan } & \multicolumn{3}{|c|}{ Pelajar } \\
\hline & & $\mathrm{J}$ & $\mathrm{N}$ & $\mathrm{R}$ \\
\hline 6 & $\begin{array}{l}\text { Dengan } \\
\text { meletakkan } \\
\text { jangka lukis pada } \\
\text { dua titik } \\
\text { persilangan, } \\
\text { lukiskan dua } \\
\text { lengkok. }\end{array}$ & $\begin{array}{l}\text { Menghasil } \\
\text { kan dua } \\
\text { lengkok. }\end{array}$ & $\begin{array}{l}\text { Tidak dapat } \\
\text { melukis } \\
\text { pembahagi } \\
\text { dua sama. }\end{array}$ & $\begin{array}{l}\text { Menghas } \\
\text { ilkan dua } \\
\text { lengkok. }\end{array}$ \\
\hline 7 & $\begin{array}{l}\text { Dengan } \\
\text { memnggunakan } \\
\text { pembaris, lukis } \\
\text { satu garis lurus } \\
\text { yang } \\
\text { menyambungkan } \\
\text { titik tersebut } \\
\text { dengan } \mathrm{S} \text {. } \\
\text { Labelkan } \angle R S U \text {. }\end{array}$ & $\begin{array}{l}\text { Menyamb } \\
\text { ungkan } \\
\text { titik } \\
\text { dengan } \mathrm{R} . \\
\text { Labelkan } \\
\angle S R U\end{array}$ & $\begin{array}{l}\text { Tidak dapat } \\
\text { melukis } \\
\text { pembahagi } \\
\text { dua sama. }\end{array}$ & $\begin{array}{l}\text { Menyam } \\
\text { bungkan } \\
\text { titik } \\
\text { dengan } \\
\text { S. } \\
\text { Labelkan } \\
\angle S R U\end{array}$ \\
\hline
\end{tabular}

Semasa melukis pembahagi dua sama untuk menghasilkan sudut $30^{\circ}$, pelajar $\mathrm{J}$ tetap dapat melakukannya dalam masa yang singkat. Akan tetapi, dia masih melakukan kesilapan dalam labelkan sudut memandangkan dia telah membuat kesilapan di bahagian A.

Pelajar $\mathrm{N}$ langsung tidak dapat melukis pembahagi dua sama walaupun telah diminta ingat kembali apa yang telah cikgu ajar dan diingatkan hubung kait antara sudut $60^{\circ}$ dan sudut $30^{\circ}$. Apabila ditanya tentang apa yang difikirkan pada masa itu, pelajar $\mathrm{N}$ mengatakan bahawa dia kurang pasti cara untuk melukis pembahagi dua sama, setelah diberi galakan untuk memcuba, dia menggunakan pembaris untuk melukis satu garis lurus antara garis RS dan garis ST. akan tetapi, dia memadamkan garis yang dilukis kerana dia berpendapat bahawa, jawapannya tidak akan dapat markah dalam peperiksaan kerana tiada tanda lengkok sebagai bukti pembinaan geometri. Pelajar R pada mulanya tidak dapat melukis pembahagi dua sama, akhirnya dia berjaya melukis pembahagi dua sama setelah diingatkan hubungan antara sudut $60^{\circ}$ dan sudut $30^{\circ}$. 
Jadual 3 Bahagian C (Membina sudut $90^{\circ}$ di $\angle P Q R$ )

\begin{tabular}{|c|c|c|c|c|}
\hline \multirow{2}{*}{ Langkah } & \multirow{2}{*}{ Penerangan } & \multicolumn{3}{|c|}{ Pelajar } \\
\hline & & $\mathrm{J}$ & $\mathrm{N}$ & $\mathrm{R}$ \\
\hline 1 & $\begin{array}{l}\text { Melukis garis } \\
\text { lurus dan } \\
\text { labelkan } \\
\text { sebagai PQ. }\end{array}$ & $\begin{array}{l}\text { Melukis garis } \\
\text { dan labelkan } \\
\text { sebagai PQ. }\end{array}$ & $\begin{array}{l}\text { Melukis } \\
\text { garis dan } \\
\text { labelkan } \\
\text { sebagai } \\
\text { QR. }\end{array}$ & $\begin{array}{l}\text { Melukis } \\
\text { garis dan } \\
\text { labelkan } \\
\text { sebagai } \\
\text { PQ. }\end{array}$ \\
\hline 2 & $\begin{array}{l}\text { Membuka } \\
\text { jangka lukis } \\
\text { dengan kadar } \\
\text { separuh dari } \\
\text { panjang garis } \\
\text { PQ. }\end{array}$ & $\begin{array}{l}\text { Membuka } \\
\text { jangka lukis } \\
\text { dengan kadar } \\
\text { melebihi separuh } \\
\text { dari panjang } \\
\text { garis PQ. }\end{array}$ & $\begin{array}{l}\text { Membuka } \\
\text { jangka } \\
\text { lukis } \\
\text { dengan } \\
\text { kadar } \\
\text { melebihi } \\
\text { separuh } \\
\text { dari } \\
\text { panjang } \\
\text { garis QR. }\end{array}$ & $\begin{array}{l}\text { Membuka } \\
\text { jangka } \\
\text { lukis } \\
\text { dengan } \\
\text { kadar } \\
\text { kurang } \\
\text { daripada } \\
\text { separuh } \\
\text { dari } \\
\text { panjang } \\
\text { garis PQ. } \\
\text { Bukaan } \\
\text { jangka } \\
\text { lukis telah } \\
\text { diubah. }\end{array}$ \\
\hline 3 & $\begin{array}{l}\text { Letakkan } \\
\text { jangka lukis } \\
\text { pada titik P } \\
\text { dan Q dan } \\
\text { lukiskan } \\
\text { lengkok. }\end{array}$ & $\begin{array}{l}\text { Letakkan jangka } \\
\text { lukis pada titik P } \\
\text { dan Q dan } \\
\text { lukiskan satu } \\
\text { lengkok di } \\
\text { bahagian atas } \\
\text { garis dan satu } \\
\text { lengkok di } \\
\text { bahagian bawah } \\
\text { garis. }\end{array}$ & $\begin{array}{l}\text { Letakkan } \\
\text { jangka } \\
\text { lukis pada } \\
\text { titik Q dan } \\
\text { R dan } \\
\text { lukiskan } \\
\text { satu } \\
\text { lengkok. }\end{array}$ & $\begin{array}{l}\text { Letakkan } \\
\text { jangka } \\
\text { lukis pada } \\
\text { titik P dan } \\
\text { Q dan } \\
\text { lukiskan } \\
\text { satu } \\
\text { lengkok. } \\
\text { Lengkok di } \\
\text { P tidak } \\
\text { bersilang } \\
\text { dengan } \\
\text { lengkok di } \\
\text { Q. }\end{array}$ \\
\hline 4 & $\begin{array}{l}\text { Dengan } \\
\text { menggunakan } \\
\text { sesiku, } \\
\text { lukiskan garis } \\
\text { menegak ke } \\
\text { titik } \\
\text { persilangan. } \\
\text { Labelkan } \\
\text { sudut } 90^{\circ} .\end{array}$ & $\begin{array}{l}\text { Lukiskan garis } \\
\text { untuk } \\
\text { menyambungkan } \\
\text { titik persilangan } \\
\text { di bahagian atas } \\
\text { dan bahagian } \\
\text { bawah garis PQ. } \\
\text { Labelkan sudut } \\
90^{\circ} \text { dengan } \\
\text { melukis satu segi } \\
\text { empat sama. }\end{array}$ & $\begin{array}{l}\text { Lukiskan } \\
\text { garis } \\
\text { menegak ke } \\
\text { titik } \\
\text { persilangan. } \\
\text { Labelkan } \\
90^{\circ} \text {. Garis } \\
\text { yang } \\
\text { dilukis } \\
\text { kelihatan } \\
\text { tidak } \\
\text { membentuk } \\
\text { sudut tegak. }\end{array}$ & $\begin{array}{l}\text { Tidak } \\
\text { dapat } \\
\text { melukis } \\
\text { garis } \\
\text { menegak } \\
\text { ke titik } \\
\text { persilangan } \\
\text { kerana } \\
\text { tiada titik } \\
\text { persilangan } \\
\text { terbentuk } \\
\text { di langkah } \\
\text { 3. }\end{array}$ \\
\hline
\end{tabular}

Pelajar J dapat membina sudut $90^{\circ}$ dengan betul walaupun dia tidak menggunakan sesiku, sebaliknya, dia melukis dua titik persilangan di atas dan bawah garis masing-masing dan berjaya menghasilkan sudut tegak pada garis lurus. Pelajar $\mathrm{J}$ melabelkan sudut yang dihasilkan sebagai $\angle R P Q$ dan bukannya $\angle P Q R$ kerana titik persilangannya melalui titik $\mathrm{P}$ dan bukannya titik $\mathrm{Q}$. 
Sudut $90^{\circ}$ yang dihasilkan oleh pelajar $\mathrm{N}$ adalah kurang tepat memandangkan dia melakukan kesilapan di langkah 4 iaitu tidak menggunakan sesiku semasa melukis garis menegak. Pelajar $\mathrm{R}$ pula tidak dapat menghasilkan sudut $90^{\circ}$ kerana dia telah mengubah bukaan jangka lukis di langkah 2. Akibatnya, lengkok yang dilukis tidak dapat menghasilkan titik persilangan.

Jadual 4 Bahagian D (Membina sudut $45^{\circ}$ dengan melukis pembahagi dua sama sudut)

\begin{tabular}{|c|c|c|c|c|}
\hline \multirow{2}{*}{ Langkah } & \multirow{2}{*}{ Penerangan } & \multicolumn{3}{|c|}{ Pelajar } \\
\hline & & $\mathrm{J}$ & $\mathrm{N}$ & $\mathrm{R}$ \\
\hline 5 & $\begin{array}{l}\text { Dengan } \\
\text { meletakkan } \\
\text { jangka lukis } \\
\text { pada titik } \\
\text { persilangan, } \\
\text { lukis satu } \\
\text { lengkok. }\end{array}$ & $\begin{array}{l}\text { Melukis } \\
\text { satu } \\
\text { lengkok. }\end{array}$ & \multirow{2}{*}{$\begin{array}{l}\text { Tidak } \\
\text { dapat } \\
\text { melukis } \\
\text { pembahagi } \\
\text { dua sama. }\end{array}$} & \multirow{3}{*}{$\begin{array}{l}\text { Tidak } \\
\text { dapat } \\
\text { melukis } \\
\text { sudut } \\
45^{\circ} \\
\text { kerana } \\
\text { tidak } \\
\text { dapat } \\
\text { melukis } \\
90^{\circ} \text { di } \\
\text { bahagia } \\
\text { n C tadi. }\end{array}$} \\
\hline 6 & $\begin{array}{l}\text { Dengan } \\
\text { meletakkan } \\
\text { jangka lukis } \\
\text { pada dua titik } \\
\text { persilangan, } \\
\text { lukiskan dua } \\
\text { lengkok. }\end{array}$ & $\begin{array}{l}\text { Melukis } \\
\text { dua } \\
\text { lengkok. }\end{array}$ & & \\
\hline 7 & $\begin{array}{l}\text { Dengan } \\
\text { menggunakan } \\
\text { pembaris, } \\
\text { lukiskan satu } \\
\text { garis lurus } \\
\text { yang } \\
\text { meyambungk } \\
\text { an titik } \\
\text { tersebut. } \\
\text { Labelkan } \\
\text { sudut } \angle P Q S \text {. }\end{array}$ & $\begin{array}{l}\text { Menyambu } \\
\text { ngkan titik } \\
\text { yang } \\
\text { dihasilkan } \\
\text { dan } \\
\text { labelkan } \\
\text { sudut } \\
\angle Q P S \text {. }\end{array}$ & & \\
\hline
\end{tabular}

Sudut $45^{\circ}$ yang dihasilkan oleh pelajar $\mathrm{J}$ adalah betul, akan tetapi labelnya adalah salah memandangkan dia telah salah melabelkan sudut $90^{\circ}$ di bahagian $\mathrm{C}$ tadi. Pelajar $\mathrm{N}$ dan pelajar $\mathrm{R}$ tidak dapat menyempurnakan bahagian $\mathrm{D}$ ini di mana pelajar $\mathrm{N}$ tidak teringat cara untuk melukis pembahagi dua sama manakala pelajar R tidak dapat melukis sudut $45^{\circ}$ kerana tidak dapat melukis $90^{\circ}$ di bahagian $\mathrm{C}$ tadi.

Melalui temubual yang dijalankan, didapati pelajar $\mathrm{J}$ mempunyai masalah dalam perlabelan walaupun dia dapat melukis setiap sudut dengan betul. Pelajar $\mathrm{N}$ pula tidak dapat melukis pembahagi dua sama tanpa menggunakan protraktor kenara tidak teringat langkah untuk melukis pembahagi dua sama. Selain itu, didapati juga pelajar $\mathrm{N}$ ini tidak tahu cara menggunakan sesiku untuk melukis garis menegak yang berserenjang dengan garis melintang. Pelajar $\mathrm{R}$ menghadapi masalah dalam melukis sudut $90^{\circ}$ kerana terkeliru dengan bukaan jangka lukis. Bukaan jangka lukis tidak boleh diubah untuk melakukan lengkok, tetapi pelajar $\mathrm{R}$ telah mengubah bukaan jangka lukisnya. Akibatnya lengkok yang dilukis tidak bersilang dan menyebabkan dia tidak dapat melukis $90^{\circ}$ di bahagian $\mathrm{C}$ dan gagal melukis $45^{\circ}$ di bahagian D.

Apabila ditanya cara untuk menyemak jawapan untuk setiap bahagian atau cara untuk mengenal pasti sudut yang dilukis adalah tepat, ketiga-tiga oleh pelajar dapat memberi jawapan yang betul iaitu dengan menggunakan protraktor. Selain itu, pelajar-pelajar turut memberi pendapat bahawa pembinaan geometri melibatkan terlalu banyak langkah dan langkah-langkah untuk pembinaan sudut berlainan adalah berbeza. Mereka mendapati hafalan langkah-langkah tersebut amat menyusahkan sedangkan mereka boleh melukis sudut-sudut tersebut dengan mudah jika menggunakan protraktor.

Hendroanto \& Fitriyani (2019) mengatakan bahawa, walaupun pelajar telah lama menggunakan alat-alat seperti jangka lukis, protraktor, dan alat tepi lurus, tetapi mereka tidak menggunakan alat-alat tersebut untuk melukis apabila diperlukan. Menurut Azlina \& Lok (n.d.), pelajar sering kali menghadapi 
masalah dalam memahami dan menguasai konsep geometri apabila mempelajari tajuk pembinaan geometri. Ini adalah sejajar dengan Laporan Trend International and Society Study (TIMSS) yang mengatakan bahawa pencapaian geometri dalam matematik murid sekolah menengah rendah di Malaysia adalah kurang memuaskan berbanding dengan pelajar sekolah menengah rendah di Negara-negara Asia Pasifik (Mohd Faizal Nizam \& Leow, 2017).

\section{KESIMPULAN}

Secara keseluruhannya, pelajar menghadapi masalah dalam pembinaan sudut. Walau bagaimanapun, kajian lanjutan perlu dijalankan yang melibatkan beberapa buah sekolah lain di daerah ini untuk mendapat gambaran yang lebih menyeluruh berhubung isu ini. Temubual yang dijalankan menunjukkan pelajar menghadapi masalah dalam perlabelan sudut dan penggunaan sesiku. Perlabelan yang salah menyebabkan sudut yang dilukis tidak menepati kehendak soalan walaupun setiap langkah pembinaan adalah betul. Sebagai contoh, kehendak soalan meminta pelajar melukis sudut $60^{\circ}$ di $\angle R S T$, bermakna sudut $60^{\circ}$ dilukis di S. Akan tetapi, pelajar melabelkan sudut $60^{\circ}$ yang dilukisnya sebagai $\angle S R T$ yang membawa maksud sudut $60^{\circ}$ di R. Selain itu, pelajar tidak menggunakan sesiku untuk melukis garis menegak untuk melukis $90^{\circ}$ yang berserenjang dengan garis melintang menunjukkan pelajar tidak pasti kegunaan sesiku. Jadi, tindakan yang sewajarnya harus diambil untuk membantu pelajar mengatasi masalah-masalah tersebut agar mereka dapat menguasai tajuk pembinaan geometri.

\section{RUJUKAN}

Abdulkadir Tuna, Cagri Biber \& Samet Korkmaz. (2013). The Mistakes and the Misconceptions of the Eight Grade Students on the Subject of Angles. European Journal of Science and Mathematics Education, 1(2), 50-59.

Azlina, M. K., \& Lok, Y. L. (n.d.). Keberkesanan perisian geometer's sketchpad untuk tajuk pembinaan geometri dalam pengajaran dan pembelajaran matematik.

Chua Yan Piaw 2006. Asas Statistik Penyelidikan. Jilid 3. Kuala Lumpur: Mc Graw Hill (Malaysia) Sdn. Bhd.

Cresswell, J.W. (2012). Educational Research: planning, conducting and evaluating quantitative and qualitative research. ( $4^{\text {th }}$ Ed.). Boston, MA: Pearson Education Inc.

Hendroanto, A., \& Fitriyani, H. (2019). Analyzing the need of math geometry drawing tools in mathematics classroom Analyzing the need of math geometry drawing tools in mathematics classroom. Journal of Physics: Conference Series, 1188, 11. https://doi.org/10.1088/1742-6596/1188/1/012051

Keith Morrison, Lawrence Manion \& Louis Cohen (2007). Research Methods in Education (6 ${ }^{\text {th }}$ Edition). Madison Avenue, New York : Routledge, Taylor \& Francis Group.

Lisa M. Given. (2008). The Sage Encyclopedia of Qualitative Research Methods. Doi : https://www.pdfdrive.com/the-sage-encyclopedia-of-qualitative-research-methods-e34331350.html

Marjorie L. DeVault, Robert Bogdan \& Steven J Taylor. (2016). Introduction to Qualitative research Methods, A Guidebook and Resource. Doi : https://www.pdfdrive.com/introduction-to-qualitative-research-methodse34555026.html

Meor Ibrahim Bin Kamaruddin \& Siti Hajar Binti Ramzan. (n.d.). Tahap Penguasaan Topik 'Lines and Angles' Dalam Kalangan Pelajar Pendidikan Matematik Di Universiti Teknologi Malaysia.

Merriam, S.B. (2001). Qualitative Research and Case Study Applications in Education. San Francisco : Jossey-Bass Publishers.

Mohd Faizal Nizam, L. A., \& Leow, T. W. (2017). Kesahan dan kebolehpercayaan instrumen penilaian kendiri pembelajaran geometri tingkatan satu. Malaysian Journal of Learning and Instruction, 14(1), 211-265.

Noraini Idris. (2013). Penyelidikan dalam Pendidikan. Kuala Lumpur: Mc Graw Hill.

Pusat Perkembangan Kurikulum (2000). Sukatan Pelajaran KBSMMatematik Tingkatan 1. Kementerian Pendidikan Malaysia.

Ranjit Kumar. (2011). Research Methodology, A Step by Step Guide for a Beginners. ( ${ }^{\text {rd }}$ Edition). London : Sage Publications.

Sarah J Tracy. (2013). Qualitative Research Methods. Doi : https://www.pdfdrive.com/qualitative-research-methodse18822833.html

Yin, R.K. (2003). Case Study Research : Design and Methods. (3 ${ }^{\text {rd }}$ Edition) . Newburry Park, CA : Sage Publication. 